\title{
Confirmation of high cytokine clearance by hemofiltration with a cellulose triacetate membrane with large pores: an in vivo study
}

\author{
P. DELANAYE ${ }^{1}$, B. LAMBERMONT 2,3, J.-M. DOGNÉ ${ }^{3,4}$, B. DUBOIS ${ }^{1}$, A GHUYSEN $^{2,3}$, N. JANSSEN ${ }^{5}$, T. \\ DESAIVE $^{3}$, P. KOLH $^{3,5}$, V. D'ORIO ${ }^{2,3}$, J.-M. KRZESINSKI ${ }^{1}$ \\ ${ }^{I}$ Department of Nephrology, University of Liège, Liège - Belgium \\ ${ }^{2}$ Department of Medicine, University of Liège, Liège - Belgium \\ ${ }^{3}$ Hemodynamic Research Laboratory, HemoLiege, University of Liège, Liège - Belgium \\ ${ }^{4}$ Department of Pharmacy, University of Namur, Namur - Belgium \\ ${ }^{5}$ Department of Surgery, University of Liège, Liège - Belgium
}

\begin{abstract}
:
Objective: To confirm in vivo the hypothesis that hemofiltration with a large pore membrane can achieve significant cytokine clearance. Method: We used a well-known animal model of endotoxinic shock $(0.5 \mathrm{mg} / \mathrm{kg}$ of lipopolysaccharide from Escherichia Coli over a period of $30 \mathrm{mins}$ ). Six pigs were hemofiltrated for 3 hours with a large pore membrane (78 ̊ pore, $80 \mathrm{kDa}$ cut off) (Sureflux FH 70, Nipro, Osaka, Japan). The ultrafiltration rate was $45 \mathrm{ml} / \mathrm{kg} / \mathrm{min}$. Samples were taken from arterial, venous line and in the ultrafiltrate at T120 and T240. We measured concentrations of interleukin 6, interleukin 10 and albumin. Results: At T120 and T240, the IL-6 clearances were $22 \pm 7$ and $15 \pm 3 \mathrm{ml} / \mathrm{min}$, respectively. The IL-6 sieving coefficients were 0.97 and 0.7 at T120 and T240, respectively. At T120 and T240, the IL-10 clearances were $14 \pm 4$ and $10 \pm 7 \mathrm{ml} / \mathrm{min}$, respectively The sieving coefficients were 0.63 and 0.45 at T120 and T240, respectively. The concentrations of IL-6 and IL-10 were the same at T0 and T240. At T60 and T240, the plasmatic albumin concentrations were 24 $\pm 4 \mathrm{~g} / \mathrm{L}$ and $23 \pm 4 \mathrm{~g} / \mathrm{L}$, respectively $(\mathrm{p}=0.13)$. Conclusions: In this animal model of endotoxinic shock, we confirm the high cytokine clearance observed when hemofiltration is applied to a large pore membrane. The loss of albumin seems negligible. The impact of such clearances on hemodynamic stability and survival remains to be proved.
\end{abstract}

Keywords: cytokine ; endotoxin ; hemofiltration ; clearance ; septic shock

\section{Introduction}

Despite recent therapeutic progress, severe sepsis-associated mortality remains high (1). Since cytokines play an important pathogenic role in sepsis (2) and their concentration is predictive of the shock gravity and global mortality (3), several authors have suggested that hemofiltration could be of interest by removing diverse proand anti-inflammatory mediators from the circulation (4-6). This theory has been called "the peak concentration hypothesis" (6). However, the most frequently used membranes have a cut off between 30 and $40 \mathrm{kDa}$ and induce no sufficient cytokines clearance (7-10). For example, the convective clearance of IL-6, one of the most important pro-inflammatory cytokines (11), is less than $2 \mathrm{ml} / \mathrm{min}$ with such membranes and an ultrafiltrate rate of $1 \mathrm{l} / \mathrm{h}$ (which corresponds to a sieving coefficient (SC) of 0.12) (9). Moreover, De Vriese et al and Heering et al measured no IL-10, one of the most important anti-inflammatory cytokines (12), in ultrafiltrate during $\mathrm{CWH}$ with such membranes $(7,8)$. A cut off membrane of $40 \mathrm{kDa}$ means a SC of 0.05 or 0.1 for a $40 \mathrm{kDa}$ molecule $(13,14)$. These results are obtained in vitro and these cut offs could be decreased by up to $40 \%$ when they are calculated in vivo (15). The molecular weight of IL-6 and 1L-10 (28 and $19 \mathrm{kDa}$ respectively) may explain the low SC and clearance rate of these cytokines with classical membranes.

Some authors have recently proposed the use of membranes with larger pores to increase effective cytokine clearances $(16,17)$. Uchino et al have demonstrated high cytokine clearance in an ex vivo model of septic shock using a cellulose triacetate membrane with large pores (78 ̊̊ diameter) (17). In our study, using a similar large pore membrane, we measured IL-6 and IL-10 clearance in a porcine model of endotoxinic shock.

\section{Materials and methods}

All experimental procedures and protocols used in this investigation were reviewed and approved by the Ethics Committee of the Medical Faculty of the University of Liège. The investigation conforms with the Guide for the Care and Use of Laboratory Animals published by the US National Institutes of Health (NIH Publication No. 8523, revised 1996).

\section{Surgical preparation}

Experiments were performed on 6 healthy pure pietran pigs of either sex weighing from 20 to $30 \mathrm{~kg}$. The 
animals were premedicated with an intramuscular administration of ketamine $(20 \mathrm{mg} / \mathrm{kg})$ and diazepam $(1 \mathrm{mg} / \mathrm{kg})$. Anaesthesia was then induced and maintained by a continuous infusion of sufentanil $(0.5 \mu \mathrm{g} / \mathrm{kg} / \mathrm{h})$ and pentobarbital $(5 \mathrm{mg} / \mathrm{kg} / \mathrm{h})$. Spontaneous movements were prevented by pancuroniurn bromide $(0.2 \mathrm{mg} / \mathrm{kg})$. After endotracheal intubation through a cervical tracheostomy, the pigs were connected to a volume-cycled ventilator (Evita 2, Dräger, Lübeck, Germany) set to deliver a tidal volume of $10 \mathrm{ml} / \mathrm{kg}$ with a FiO $\mathrm{O}_{2}$ of 0.4 and at a respiratory rate of 20 breaths $/ \mathrm{mm}$. End-tidal $\mathrm{CO}_{2}\left(\mathrm{PETCO}_{2}\right)$ measurements $($ Capnomac, Datex, Helsinki, Finland) were used to monitor the adequacy of ventilation. Respiratory settings were adjusted to maintain $\mathrm{PETCO}_{2}$ between 30 and $35 \mathrm{mmHg}$. A 12F double lumen dialysis catheter (Arrow International, Reading, PA, USA) was inserted through a left femoral venotomy.

\section{Experimental protocol}

The animals received a $0.5 \mathrm{mg} / \mathrm{kg}$ endotoxin infusion (Lipopolysaccharide from Escherichia Coli serotype 0127:B8; Sigma Chemical, St Louis, MO) over 30 mins (from T0 to T30). This model of endotoxinic shock has been previously validated and is reproducible (18). They underwent, from T60 onwards, a zero-balance continuous veno-venous hemofiltration at a rate of $45 \mathrm{ml} / \mathrm{kg} / \mathrm{h}$. A $0.7 \mathrm{~m}^{2}$, large pore (78 $\AA$ ) membrane with a cut off of $80 \mathrm{kDa}$ (Sureflux FH 70, Nipro, Osaka, Japan) and a Baxter BM 25-BM 14 hemofiltration device (Baxter Health Care, Munich, Germany) were used. Blood flow through the membrane was calculated with the following equation:

$$
\text { Blood flow }(\mathrm{ml} / \mathrm{min})=U F(\mathrm{ml} / \mathrm{min}) \times 3.5 \text {. }
$$

Ultrafiltrate was replaced in the post-dilution mode by a bicarbonate-buffered hemofiltration fluid $\left(\mathrm{Na}^{+}: 150\right.$ $\mathrm{mmol} / \mathrm{L}, \mathrm{K}^{+}: 3 \mathrm{mmol} / \mathrm{L}$, bicarbonate: $30 \mathrm{mmoi} / \mathrm{L}$ ) at a temperature of $37^{\circ} \mathrm{C}$. Anticoagulation of the extracorporeal circuit was achieved using a loading dose of 5000 IU heparin followed by an anticoagulation regimen based on the activated clotting time $(100-200 \mathrm{~s})$. The calcium chloride $(100 \mathrm{mg} / \mathrm{mL})$ infusion rate was calculated with the following equation:

$$
\mathrm{CaCl}_{2} \text { infusion rate }(\mathrm{ml} / \mathrm{h})=\mathrm{UF}(\mathrm{ml} / \mathrm{h}) \times 1.2 / 1000 \text {. }
$$

\section{Cytokine clearance}

Blood (before and after the membrane) and ultrafiltrate samples were taken at T0, T60, T120 and T240 to measure IL-6 (28 kDa), and IL-10 (19 kDa) concentrations using an ELISA test (Biosource, Paris, France). We calculated their clearance and SC at T120 and T240 with a classical formula: SC $=2 \mathrm{X}[\mathrm{UF}] /[\mathrm{A}]+[\mathrm{V}]$ and clearance $=\mathrm{SC} X$ ultrafiltration rate $(\mathrm{ml} / \mathrm{min})$, where $[\mathrm{UF}]$ is the concentration in ultrafiltrate, $[\mathrm{A}]$ is the concentration in inlet supernatant and [V] the concentration in outlet supernatant. Plasmatic albumin concentration was measured at T60 and T240 (with the bromocresol green method).

Data are presented as mean \pm standard deviation (SD). The values have been compared with the classical Wilcoxon test (MedCalc Software, Mariakerke, Belgium). P < 0.05 was considered statistically significant.

\section{Results}

At T120 and T240, the IL-6 clearances were $22 \pm 7$ and $15 \pm 3 \mathrm{ml} / \mathrm{min}$, respectively. The IL- 6 sieving coefficients were 0.97 and 0.7 at T120 and T240, respectively.

At T120 and T240, the IL-10 clearances were $14 \pm 4$ and $10 \pm 7 \mathrm{ml} / \mathrm{min}$, respectively. The sieving coefficients were 0.63 and 0.45 at T120 and T240, respectively. All the results are summarized in Table I.

The concentration of IL-6 and IL-10 were the same at T0 and T240.

At T60 and T240, the plasmatic albumin concentrations were $24 \pm 4 \mathrm{~g} / \mathrm{L}$ and $23 \pm 4 \mathrm{~g} / \mathrm{L}$, respectively $(\mathrm{p}=0.13)$.

Table I - Summary of the clearances and sieving coefficient (SC) of cytokines IL-6 and IL-10 at T120 (after one hour of hemofiltration) and at T240 (after three hours of hemofiltration) using a large pore membrane

\begin{tabular}{|lllll|}
\hline \multicolumn{2}{c}{ T120 } & & \multicolumn{2}{c|}{ T240 } \\
& Clearance (ml/min) & SC & Clearance (ml/min) & SC \\
\hline IL-6 & $22 \pm 7$ & 0.97 & $15 \pm 3$ & 0.7 \\
\hline IL-10 & $14 \pm 4$ & 0.63 & $10 \pm 7$ & 0.45 \\
\hline
\end{tabular}


Published in: International Journal of Artificial Organs (2006), vol. 29, iss. 10, pp. 944-948.

Status : Postprint (Author's version)

\section{Discussion}

Our results show a high SC and a high clearance rate for IL-6 and IL-10 with a large pore membrane and confirm, in vivo, those recently published by Uchino et al in an ex vivo study (17). IL-6 SC and clearances are 5 or 6 times higher than those obtained with classical membranes (7-9). Our results with IL-10 are also of interest because other authors have described a SC of 0 with a classical membrane (7). Despite a higher molecular weight, SC values of IL-6 are superior to those of IL-10. Actually, the molecular weight is not the only factor which explains crossing through the membrane. For example, it is well known that, despite a low molecular weight $(8 \mathrm{kDa})$, interleukin 8 does not cross through the classical membranes because it binds the heparin present in the circuit (19).

In septic patients, Morgera et al have recently described high SC and clearance for IL-6 (SC of 0.48 and clearance, at $8 \mathrm{ml} / \mathrm{min}$ at an ultrafilration rate of $1 \mathrm{l} / \mathrm{h}$, after 4 hours) but they used another synthetic membrane (Polyflux, Gambro) (20). Morgera et al and Uchino et al have also shown that the cytokine clearance increases when the ultrafiltration rate increases (even if the SC decreases) $(17,20)$. Others have studied membranes with higher cut off values (around $100 \mathrm{kDa}$ ). Their results show high SC and clearances, but albumin loss becomes significant $(13,14,16,21-23)$. With the membrane used in our study, albumin loss is timely and quantitatively limited $(17,20)$. We have not noted any decrease in albumin concentration.

Our study has several limitations. We did not study the adsorption of the membrane. However, it is well known that adsorption is very limited with ail membranes composed of cellulose triacetate due to their specific physicochemical properties (24-26). This seems also the case with cellulose triacetate and large pore membranes, as illustrated by Uchino (17), Secondly, we have measured the concentration, clearance and SC of only two cytokines. Although IL-6 and IL-10 are two of the most important inflammatory mediators, other mediators, like $\mathrm{TNF} \alpha$, could have been studied. Due to its relatively high molecular weight (active, trimeric, TNF $\alpha$ has a molecular weight of $51 \mathrm{kDa}(27)$ ), the TNF $\alpha \mathrm{SC}$ should be theoretically low. Uchino et al have found a SC value of 0.34 for TNF $\alpha$ and Morgera et al, with another large pore membrane, have found a SC value of 0 for TNF $\alpha$ $(17,20)$. Moreover, it should be stressed that TNF $\alpha$ is a very early and transient inflammatory marker in severe sepsis, making it an undesirable therapeutic target $(9,20)$.

Although we have confirmed the high cytokine clearances obtained with large pore membranes, its beneficial effects on hemodynamics and survival remains to be demonstrated in severe sepsis. Indeed, the "peak concentration hypothesis" is not the only hypothesis to explain hemodynamic improvement and better survival observed with hemofiltration (especially with high volume hemofiltration) $(28,29)$. Until now, little data has been published on large pore membranes. Nevertheless, Lee et al have shown a better survival of swine with severe sepsis (Staphylococcus aureus induced septicaemia) after continuous arteriovenous hemofiltration with a large pore membrane (cut off of $100 \mathrm{kDa}$ ). However, these authors did not measure cytokine clearances (30).

While using cellulose triacetate membrane with large pores induces a significant cytokine clearance by hemofiltration, animal and human protocols studying the impact of such membrane on hemodynamic stability and on survival are still awaited.

\section{Acknowledgements}

The authors would like to thank Philippe Devel, Michèle Focan and Marie-Antoinette Graceffa for their technical assistance.

This work was supported by a Grant from Nipro Europe, Zaventem, Belgium. Philippe Kolh is a recipient of a postdoctoral grant from the Fonds National de la Recherche Scientifique.

\section{References}

1. Friedman G, Silva E, Vincent JL. Has the mortality of septic shock changed with time, Crit Care Med 1998; 26: 2078-86.

2. Parrillo JE. Pathogenetic mechanisms of septic shock. N Engl J Med 1993; 328: 1471-7.

3. Simmons EM, Himmelfarb J, Sezer MT, et al. Plasma cytokine levels predict mortality In patients with acute renal failure. Kidney Int 2004; 65: 1357-65.

4. Journois D, Israel-Biet D, Pouard P, et al. High-volume, zero-balanced hemofiltration to reduce delayed inflammatory response to cardiopulmonary bypass In children. Anesthesioiogy 1996; 85: 965-76.

5. Groeneveld AB. Septic shock and multiple organ failure: treatment with haemofiltration? Intensive Care Med 1990; 16: 489-90.

6. Ronco C, Tetta C, Mariano F, et al. Interpreting the mechanisms of continuous renal replacement therapy in sepsis: the peak concentration hypothesis. Artif Organs 2003; 27: 792-801.

7. De Vriese AS, Cofardyn FA, Philippe JJ, Vanholder RC, De Sutter JH, Lamefre NH. Cytokine removal during continuous hemofiltration in septic patients. J Am Soc Nephrol 1999; 10; 846-53.

8. Heering P, Morgera S, Schmitz FJ, et al. Cytokine removal and cardiovascular hemodynamics In septic patients with continuous venovenous hemofiltration. Intensive Care Med 1997; 23: 288-96. 
Published in: International Journal of Artificial Organs (2006), vol. 29, iss. 10, pp. 944-948.

Status : Postprint (Author's version)

9. Kellum JA, Johnson JP, Kramer D, Palevsky P, Brady JJ, Pinsky MR. Diffusive vs. convective therapy: effects on mediators of inflammation In patient with severe systemic inflammatory response syndrome. Crit Care Med 1998; 26: 1995-2000.

10. Sander A, Armbruster W, Sander B, Daul AE, Lange R, Peters J. Hemofiltration increases IL-6 clearance In early systemic inflammatory response syndrome but does not alter IL-6 and TNF alpha plasma concentrations. Intensive Care Med 1997; 23: 878-84.

11. Pathan N, Hemingway CA, Alizadeh AA, et al, Role of Interleukin 6 in myocardial dysfunction of meningococcal septic shock. Lancet 2004; 363: 203-9.

12. Marchant A, Deviere J, Byl B, De Groote D, Vincent JL, Goldman M. Interleukin-10 production during septicaemia. Lancet 1994; 343 : $707-8$.

13. Uchino S, Bellomo R, Goldsmith D, et al. Super high flux hemofiltration: a new technique for cytokine removal. Intensive Care Med 2002; $28: 651-5$

14. Morgera S, Haase M, Rocktaschel J, et al. High permeability haemofiitration improves peripheral blood mononuclear cell proliferation in septic patients with acute renal failure. Nephrol Dial Transplant 2003; 18: 2570-6.

15. Gohl H, Buck R, Strathmann H. Basic features of the polyamide membranes, Contrib Nephrol 1992; 96; 1-25.

16. Morgera S, Klonower D, Rocktaschel, J et al. TNF-alpha elimination with high cut-off haemofilters: a feasible clinical modality for septic patients? Nephrol Dial Transplant 2003; 18: 1361-9.

17. Uchino S, Bellomo R, Goldsmith D, et al. Cytokine removal with a large pore cellulose triacetate filter: an ex vivo study. Int J Artif Organs 2002; $25: 27-32$.

18. Lambermont B, Kolh R Detry O, Gerard P, Marcelle R, D'Orio V. Analysis of endotoxin effects on the intact puimonary circulation. Cardiovasc Res 1999; 41: 275-81

19. Webb LM, Ehrengruber MU, Clark-Lewis I, Baggiolini M, Rot A, Binding to heparan sulfate or heparln enhances neutrophil responses to interleukin 8, Proc Natl Acad Sci U S A 1993; 90: 7158-62.

20. Morgera S, Slowinski T, Melzer C, et al. Renal replacement therapy with high-cutoff hemofilters: Impact of convection and diffusion on cytokine clearances and protein status. Am J Kidney Dis 2004; 43: 444-53.

21. Lee WC, Uchino S, Fealy N, et al. Super high flux hemodialysls at high diaiysate flows: an ex vivo assessment. Int J Artif Organs 2004; 27: $24-8$.

22. Morgera S, Rocktaschel J, Haase M, et al. intermittent high permeability hemofiltration in septic patients with acute renal failure, intensive Care Med 2003; 29: 1989-95.

23. Mariano F, Fonsato V, Lanfranco G, et al. Tailoring high-cutoff membranes and feasible application in sepsis-associated acute renal failure: in vitro studies. Nephrol Dial Transplant 2005; 20: 1116-26.

24. Lonnemann G, Koch KM, Shaldon S, Dinarello CA. Studies on the ability of hemodialysis membranes to induce, bind, and clear human interleukin-1. J Lab Clin Med 1988; 112: 76-86.

25. Goldfarb S, Golper TA. Proinflammatory cytokines and hemofiltratlon membranes. J Am Soc Nephrol 1994; 5: 228-32.

26. Honore PM, Matson JR. Hemofiltratlon, adsorption, sieving and the challenge of sepsis therapy design. Crit Care 2002; 6: 394-6.

27. Wingfieid P, Pain RH, Craig S. Tumour necrosis factor is a compact trimer. FEBS Lett 1987; 211: 179-84.

28. Di Carlo JV, Alexander SR. Hemofiltration for cytokine-driven illnesses: the mediator delivery hypothesis. Int J Artif Organs 2005; 28: 777-86.

29. Honore PM, Joannes-Boyau O. High volume hemofiltration (HVHF) in sepsis: a comprehensive review of rationale, clinical applicability, potential indications and recommendations for future research, int J Artif Organs 2004; 27: 1077-82.

30. Lee PA, Weger GW, Pryor RW, Matson JR. Effects of filter pore size on efficacy of continuous arterlovenous hemofiltration therapy for Staphylococcus aureus-induced septicemia in immature swine. Crit Care Med 1998; 26: 730-7. 